\title{
A Review of Hypersonics Aerodynamics, Aerothermodynamics and Plasmadynamics Activities within NASA's Fundamental Aeronautics Program
}

\author{
Manuel D. Salas* \\ NASA Langley Research Center, Hampton, VA 23681
}

The research program of the aerodynamics, aerothermodynamics and plasmadynamics discipline of NASA's Hypersonic Project is reviewed. Details are provided for each of its three components: 1) development of physics-based models of non-equilibrium chemistry, surface catalytic effects, turbulence, transition and radiation; 2) development of advanced simulation tools to enable increased spatial and time accuracy, increased geometrical complexity, grid adaptation, increased physical-processes complexity, uncertainty quantification and error control; and 3) establishment of experimental databases from ground and flight experiments to develop better understanding of high-speed flows and to provide data to validate and guide the development of simulation tools.

\section{Introduction}

NASA's Aeronautics Program has undergone a comprehensive restructuring in order to pursue long-term, cutting-edge research for the benefit of the broad aeronautics community. The Aeronautics Program consists of three programs, Fundamental Aeronautics, Aviation Safety and Airspace Systems. Within its Fundamental Aeronautics Program, NASA is conducting research in four broad projects that are known as: 1) Subsonic Fixed Wing; 2) Subsonic Rotary Wing; 3) Supersonic; and 4) Hypersonics. Within the Hypersonics Project several critical disciplines are being addressed. In this paper the research plans of the Aerodynamics, Aerothermodynamics and Plasmadynamics (AAP) discipline of the Hypersonics Project [1] are reviewed.

The need for NASA's Hypersonic Project is based on the fact that all access to earth or planetary orbit, and all entry into the earth's atmosphere or any other planetary body with an atmosphere from orbit or super-orbital velocity require flight through the hypersonic regime. The severity of the hypersonic environment was painfully illustrated when on February 1, 2003 a hole in the thermal protection system (TPS) of the left wing of the Space Shuttle Columbia allowed hot gases to reach the interior of the craft and destroyed the vehicle on reentry. If the United States wishes to continue to advance its capabilities for space access, entry, and high-speed flight within any atmosphere, improved understanding of the hypersonic flight regime, see Fig. 1, and development of improved technologies to withstand and take advantage of this environment are required. The objective of the research conducted under the AAP discipline is in direct support of

\footnotetext{
* Associate Principal Investigator for Aerodynamics, Aerothermodynamics and Plasmadynamics of the Hypersonics Project, Mail Stop 499.
} 
developing and validating predictive tools to enable NASA critical missions such as the Highly Reliable Reusable Launch Systems (HRRLS) and the High Mass Mars Entry Systems (HMMES).

The AAP program of research has three major components: 1) development of physics-based models of non-equilibrium chemistry, surface catalytic effects, turbulence, transition and radiation; 2) development of advanced simulation tools to enable increased spatial and time accuracy, increased geometrical complexity, grid adaptation, increased physical-processes complexity, uncertainty quantification and error control; and 3) establishment of experimental databases from ground and flight experiments to develop better understanding of high-speed flows and to provide data to validate and guide the development of simulation tools. The proposed effort lays the foundation for the efficient use of high-fidelity tools in design and optimization, but work on this area is beyond the current 5-years horizon of the project.

The AAP program is carried out with the support of four NASA centers, Langley, Ames, Glenn and Dryden, in collaboration with several partnerships, such as the (Force Application and Launch from the Continental U.S. (FALCON), Hypersonic International Flight Research Experiment (HIFiRE), and Hypersonic Boundary Layer Transition (HyBoLT) projects, and through research investments with academia and the private sector.

\section{Highly Reliable Reusable Launch Systems}

The HRRLS builds on work conducted under NASA's Next Generation Launch Technology Program [2]. The current state-of-the-art reliability of launch vehicles is approximately 1 loss in 50 missions for expendable vehicles and less than 1 in 100 for manned systems such as the Space Shuttle. The design space for these systems includes rocket-propelled, hypersonic airbreathing (scramjet) and hybrid systems in single- and two-stage configurations. With reliability as a figure of merit, airbreathing systems out perform all rocket systems by orders of magnitude [3], but require a greater degree of technology development and tight coupling of aerodynamics and propulsion. Critical to HRRLS is the prediction of aerodynamic and aeroheating characteristics during stage separation, which involves multiple bodies, flow separation and complex shock interactions problems with localized heating, and problems associate with sharp leading edges. Equally important is the design of TPS. Hypersonic air-breathing vehicles spend most of their atmospheric flight at conditions that make the boundary layer transitional [4]. TPS design is strongly dependent on detail knowledge of boundary layer transition and surface heating loads.

\section{High Mass Mars Entry Systems}

The US Viking missions to Mars began in 1976 and every subsequent Mars landing mission has been based on the technologies developed for Viking. The aerodynamic shape of all of these missions has been a variation of the 70-degree sphere cone aeroshell of the first Viking mission with a TPS based on the SLA-561V material [5]. The Mars Science Laboratory (MSL) scheduled for launch in 2009 with an entry 
mass of $2800 \mathrm{~kg}$ ( 0.75 tons) and based on Viking aeroshell shape and TPS material would be pushing the limits of this technology. Current plans for human exploration call for an increase of two orders of magnitude in landed mass, four orders of magnitude increase in landing accuracy with the possibility of a landing site in the highlands of Mars. The largest challenge posed by Mars entry is its thin atmosphere, approximately .01 the Earth's density. It is thick enough to create thermal heating problems, but too thin for good safety margins for hypersonic deceleration and low terminal velocities. Another challenge posed by the Mars atmosphere is our current poor knowledge of its variability and composition with altitude and with the seasons. Designers of entry vehicles pay close attention to the hypersonic ballistic coefficient:

$$
\beta=\frac{m}{C_{D} A},
$$

defined by the mass of the entry vehicle, its drag coefficient, and its reference area. They like low ballistic coefficients to keep the heating rate low and permit hypersonic deceleration at higher altitudes. The first Viking mission had a ballistic coefficient of 64 $\mathrm{kg} / \mathrm{m}^{2}$ and MSL will have a ballistic coefficient of $115 \mathrm{~kg} / \mathrm{m}^{2}$. The challenge of future aeroshell shape design is to obtain high $\mathrm{L} / \mathrm{D}$ to allow maneuvering while keeping $\beta$ low. High $\beta$ and high diameter shells will incur additional aerothemodynamcs heating due to radiation and boundary layer transition [6]. TPS design requires extensive experimental validation due to current modeling uncertainties [7]. Aft-body TPS design is further complicated by unsteady separated flow and wake interactions with reaction control systems (RCS) thrusters. Typical flow features associated with a reentry shell shape are shown on Fig. 2.

\section{Physics-based models}

In addition to the usual models of turbulence and transition that are required at low speed, at hypersonic speed models are needed to characterize the equation of state, chemical kinetics (equilibrium and nonequilibrium), thermal state of species, transport properties of diffusion models, surface catalysis, radiation and others [8], [9], [2]. In what follows we describe in some detail the AAP discipline focus on models for boundary layer transition, chemical kinetics and radiation.

\subsection{Laminar to turbulent transition modeling}

The laminar boundary layer can be excited by disturbances originating on the surface or in the free stream. The disturbances on the surface are usually created by protuberances, roughness, waviness, rapid changes in curvature, degradation of the surface due to gas-surface interactions such as ablation, and other effects such as surface vibration, heating and suction. The free-stream disturbances include, among others, atmospheric turbulence and vorticity fluctuations, particulates, acoustic waves and electrostatic discharge. Under the right conditions, small-amplitude stationary and/or non-stationary disturbances entering the boundary layer can amplify either exponentially or algebraically until nonlinear effects come into play. Alternatively, the disturbances 
may be sufficiently strong to begin with, such that the linear growth phase is bypassed and turbulence occurs rather rapidly. The problem is further complicated by the fact that several instability mechanisms are possible, among them: attachment line instability, Mack's first- and second-mode streamwise instabilities, crossflow instabilities in 3D boundary layers, and Görtler instability over regions of concave curvature. For hypersonic flows, the region between the onset of transition and the onset of fully developed turbulent flow (i.e., the transition region) can be quite long, sometimes of the order of the length of the vehicle. Because of the multitude of instability modes and the various ways in which each of those may be triggered, a general model of laminar to turbulent transition would probably never be realized.

Due to their limited range of validity, simple parameter correlations, such as correlations based on Mach number, Reynolds number and some external-disturbance parameter, are accompanied by a substantial degree of uncertainty in cases involving excursions from the measurement database underlying those correlations [10]. Nonetheless, in many hypersonic applications, simple correlations are the only tools available. A case in point is the tool developed for transition prediction in support of the Space Shuttle return to flight [12]. This tool consists of a correlation of transition data for protuberances and cavities, which was acquired in conventional ground facilities and calibrated against the small amount of available flight data for the Space Shuttle. The tool is currently being used for making recommendations as to fly-as-is or to repair the surface damage prior to the return flight.

For flows dominated by a benign disturbance environment and linear growth of instability modes, transition onset correlations based on the integrated amplification of the wave amplitude (i.e., $e^{N}$ type methods) offer the next level of sophistication [13]. The $e^{N}$ method represents to a large degree the state of the art of physics based transition prediction methods across a wide range of Mach numbers. For transition scenarios involving extensive regions of nonlinear disturbance growth leading up to strong amplification of high-frequency secondary instabilities, more sophisticated methods based on the Nonlinear Parabolized Stability Equations (NPSE) will be preferable [14]. The NPSE are obtained by parabolizing the nonlinear disturbance equations and, like the Parabolized Navier Stokes Equations, can be solved by a spatial marching technique as long as the stability problem is governed by downstream propagating signals. To obtain further insight into the mechanism of transition (regardless of whether it is initiated by linear instabilities or bypass mechanisms), one has to resort to Direct Numerical Simulations (DNS) of transition [15]. For hypersonic flows, this represents a substantial challenge.

As part of the ongoing AAP discipline effort, research is being conducted into all of the methods outlined above with an emphasis on the linear and nonlinear PSE and DNS methods. The AAP discipline is currently funding multi-year research efforts at Stanford University and at the University of California, Los Angeles to develop and validate DNS capability for transition due to discrete roughness, ablation effects, real-gas effects, and surface suction and blowing. The expectations are that we will be able to identify and characterize the key transition mechanisms in these cases, which could be 
subsequently incorporated into simpler models. The drawback of this approach is the need for accurate initial and boundary conditions and the restrictions on geometric complexity and the magnitude of the Reynolds number due to algorithmic and hardware limitations, respectively.

\subsection{Chemical kinetics modeling}

The simulation of real gas effects requires extensive chemical data to model the chemical reactions, the internal energies and the interaction terms connecting them. In the Earth atmosphere $\mathrm{O}_{2}$ begins to dissociate at $2000^{\circ} \mathrm{K}, \mathrm{N}_{2}$ begins dissociation at $4000^{\circ} \mathrm{K}$, $\mathrm{O}$ and $\mathrm{N}$ begin to ionize at $9000^{\circ} \mathrm{K}$. Chemistry models and chemical databases for the Earth and Martian atmospheres are available in the literature; however in many cases the data contains large uncertainties. The reaction rate and internal energy transfer rate constants are evaluated from experiments, models with adjustable parameters, or from ab initio calculations that involve quantum chemistry calculations.

The current focus of the AAP discipline effort is to develop accurate databases for $\mathrm{N}_{2}, \mathrm{CO}_{2}, \mathrm{CO}, \mathrm{CN}$ and $\mathrm{C}_{2}$ chemistry. This effort is a cooperative effort lead by W. M. Huo, of Huo Consulting, and NASA researchers. The effort is directed at a detailed study of the chemistry of $\mathrm{N}_{2}, \mathrm{CO}_{2}, \mathrm{CO}, \mathrm{CN}$ and $\mathrm{C}_{2}$ and the following studies are representative of the effort:

- Calculation of energy transfer rates for $N_{2}\left(v_{1}, J_{1}\right)+M \rightarrow N_{2}\left(v_{1}^{\prime}, J_{1}^{\prime}\right)+M$, where $v$ and $J$ denote the vibrational and rotational states and M includes $N_{2}$, $\mathrm{N}, \mathrm{O}_{2}$, and $\mathrm{O}$. In the case of $\mathrm{M}$ being $\mathrm{N}_{2}$ or $\mathrm{O}_{2}$, its $(v, \mathrm{~J})$ states are accounted for explicitly. In the past these energy transfer rate constants have been estimated using simplified models. Accurate values are lacking.

- Calculation of dissociation rate constants for $N_{2}\left(v_{1}, J_{1}\right)+M \rightarrow N+N+M$. M includes $\mathrm{N}_{2}, \mathrm{~N}, \mathrm{~N}^{+}, \mathrm{O}_{2}$, and $\mathrm{O}$. For $\mathrm{N}_{2}$ dissociation rates Candler and Olejniczak [16] have shown that over the temperature range of interest $\left(5000^{\circ}-10000^{\circ} \mathrm{K}\right)$ there is an order of magnitude uncertainty in the rate constant of various databases.

- Calculation of dissociation rate constants for $\mathrm{CO}_{2}+\mathrm{Ar} \rightarrow \mathrm{CO}+\mathrm{O}+\mathrm{Ar}$ and for $\mathrm{CO}+\mathrm{O} \rightarrow \mathrm{C}+\mathrm{O}_{2}$ and $\mathrm{CO}+\mathrm{O} \rightarrow \mathrm{C}+\mathrm{O}+\mathrm{O}$. Radiation from the products of these reactions, $\mathrm{CO}, \mathrm{C}$ and $\mathrm{O}$, is prominent in Mars entry. The study of $\mathrm{CO}_{2}$ dissociation is to determine if the radiative state of $\mathrm{CO}$ can be produced directly by the dissociation process, a feature not tested by previous experiments. There is an order of magnitude uncertainty in the experimental data for the second and third reactions.

- Calculation of electron impact excitation cross sections of selected states of the ablation products of $\mathrm{CN}$ and $\mathrm{C}_{2}$ and calculation of electron impact ionization cross sections for $\mathrm{N}, \mathrm{O}, \mathrm{N}_{2}, \mathrm{O}_{2}$, and $\mathrm{NO}$. At present the $\mathrm{CN}$ excitation cross section is assumed to be the same as $\mathrm{NO}$ and $\mathrm{C}_{2}$ is not accounted for. For electron impact ionization, current data for atoms are based 
on classical estimates and have large uncertainties. Current models do not account for molecular ionization.

- Studying the coupling of vibration, translation and free electrons and the choice of vibrational and free electron temperatures in high enthalpy $\mathrm{N}_{2}$ gas. Currently several models are available for relating vibrational and free electron temperatures resulting in different radiation intensities. This study will help determine the best model.

The calculations described above are based on solving the Schrödinger equation at a large number of nuclear geometries (20,000 to 30,000 points) to determine the interaction potential. An analytic fit of the discrete interaction potential is then used in the Hamilton's equation describing the nuclear motion to obtain the reaction rates. Quasiclassical trajectory calculations based on the Hamilton's equation are used to bypass the slow convergence of the Schrödinger equation in the calculation of energy transfer among the vibrational energy levels in the $\mathrm{N}_{2}-\mathrm{N}_{2}$ system, see [17] for more details.

\subsection{Radiation modeling}

The need for accurate prediction of radiative heating was expressed by Gnoffo [9]: "Advanced materials for thermal protection systems in conjunction with large aerobrake diameters offer the possibility of nonablating, reusable aerobrakes. The large diameters reduce convective heating but increase radiative heating. However, the present uncertainty in nonequilibrium radiative heating component of the total heating to such aerobrakes is sufficiently large to severely compromise design options for reusable TPS.” Radiative heating calculations require the solution of the radiative transfer equation (RTE) [18], a five-dimensional integro-differential equation, at thousands of spectral frequencies, and since radiation is attenuated as it travels through the flow, the radiation intensity has to be closely coupled to every point in the flow field line of sight. As might be expected, the solution of the RTE coupled to the flow solver is both mathematically complex and computationally intensive. In order to reduce the computational complexity most radiation heating calculations today use simple line-of-sight or tangent-slab (onedimensional model with properties varying only in the transverse direction) approximate models [19], [20]. To advance the state-of-the-art, the AAP discipline is supporting research at the Pennsylvania State University to develop an efficient, high fidelity radiation code. The key components of this effort are:

- Implementation of the full-spectrum k-distribution method [21]. This method originated in the atmospheric and combustion sciences. It uses a reordering of the absorption coefficient to reduce the number of RTE evaluations by 4 to 5 orders of magnitude without affecting the accuracy of the results.

- A spherical harmonics RTE solver will be tightly coupled into both Direct Simulation Monte Carlo (DSMC) solvers and Navier-Stokes solvers. The spherical harmonics method is a high-order spectral method for the solution of the RTE [22]. 
- An overlay technique will be developed to model spallation particulates in the Navier-Stokes solvers. This technique has been used to study soot transport on rocket plumes [23].

- The new capability will be validated using data from Stardust and Apollo missions.

\section{Simulation tool development}

CFD simulations of vehicles flying at hypersonic speeds are extremely challenging. In addition, since we have "limited ability to adequately represent hypersonic flow experimentally, the challenge for hypersonic CFD predictions become even more difficult because substantial experimental data for a variety of flows and flight conditions are not available" [4] for validation. Among the outstanding issues in hypersonic flow simulation are: incorporation of boundary layer transition location models, simulation of ablation and other gas-surface interactions, accurate modeling of radiation (see §4.3), accurate simulation of time-dependent separated flows, turbulent transport in the presence of real gas effects, handling of complex geometries and control surfaces, simulation of RCS jets, accurate simulation of localized heating due to jet and shock impingement, grid adaptation to resolve critical flow features such as shocks and shear layers, and quantification of errors and modeling uncertainties. Many of these needed capabilities further complicate the numerical techniques needed by making the equations extremely stiff and difficult to integrate in time.

Today the state-of-the-art for hypersonic flow simulations consists of second order discretization, shock capturing, schemes on structured grids with some limited, but rapidly advancing, capabilities with unstructured grids. Representatives of the structured grid codes are the LAURA (Langley Aerothermodynamic Upwind Relaxation Algorithm) [24] and DPLR (Data-Parallel Line Relaxation) [25] codes. Both of these codes are highly advanced, highly tested and both are parallel implicit methods using multi-block grid topology. The US3D (UnStructured 3D) [26] code represents the state-of-the-art for unstructured codes for hypersonic flows. Two common problems of these state-of-the-art codes are: 1) high levels of dissipation making them poor candidates for Large Eddy Simulation (LES); and 2) inadequate grid convergence properties. For a detailed comparison of forebody convective and radiative heating predictions capabilities for these three codes see [27].

To advance the current state-of-the-art, the AAP discipline is supporting research in h-p multigrid, unstructured, discontinuous Galerkin methods, high-order unstructured spectral difference methods using Runge-Kutta and Newton-Krylov schemes for time advancement, adaptive numerical dissipation control, adaptive grid refinement and uncertainty quantification and control. The adaptive grid refinement and uncertainty quantification work leverages adjoint and error estimation efforts that are common to other Projects within Fundamental Aerodynamics. It is expected that the new methods will result in substantial gains in computational efficiency, flexibility and reliability for LES and DNS simulations. 
Work is also underway to advance the state-of-the-art capabilities in modeling the non-continuum flow regime. Today DSMC [28] is the main tool for simulation in this flow regime. Research is under way to develop new methods that are more efficient than DSMC and that can bridge the gap between the continuum (Navier-Stokes simulation) and non-continuum (particle simulation) [29].

The CFD work is being conducted at the Langley, Ames and Glenn Research Centers and in collaboration with the University of Minnesota and the University of Wyoming. For more details see Ref. [30].

\section{Experimental databases}

Experimental work in ground base facilities and in flight in support of modeling and CFD validation is being conducted across a wide range of topics. Three of these activities are described here.

\subsection{Experimental studies of base-flow about blunt reentry vehicles}

The AAP discipline is supporting research at the LENS II CALSPAN facility [31] to obtain laminar, transitional and base flows on large-scale model sizes of HMMES-like reentry capsules. The LENS II facility operates in the Mach number range of 3 to 10 and Reynolds number range of $10^{5}$ to $10^{10}$ per meter with a test time of up to $100 \mathrm{~ms}$. The objective is to evaluate and improve current models of transitional and turbulent flows and flow chemistry used to predict aerothermal loads in air, carbon dioxide, and other planetary environments. The tests planned will include studies of the effects of the support system. To this end, experiments with conventional sting-mounting, see Fig. 3, wire-mounting and free-flying support will be conducted. Measurements of surface pressure and surface heat transfer are planned. Both mean and fluctuation measurements are planned to provide data for both Reynolds averaged and LES simulations. Schlieren video photography will provide flow field diagnostic information about shock wave structure and global flow field features in the wake of the capsule. The effects of RCS jets in all support arrangements, using nitric-oxide as a gas tracer, will be investigated. In collaboration with NASA, planar laser-induced fluorescence [32] diagnostic testing is planned.

\subsection{Experimental studies of isolated roughness}

The AAP discipline is supporting research at the hypersonic quiet-flow Ludwieg tube wind tunnel [33] of Purdue University. The tunnel is the only operational highReynolds number $\left(11.5 \times 10^{6}\right.$ per meter) hypersonic (Mach 6) quiet tunnel in the world. The tunnel provides a 6 to 10 seconds runtime about once per hour with a typical quiet interval of about 7 seconds, the interval depends on the stagnation pressure. The planned experiment will place a roughness element within the laminar boundary layer of the tunnel wall at a location of about 74 inches from the throat. The boundary-layer profile at this location is already known from a previous study [34]. The boundary layer thickness is about 3/4 inches at 20-psia stagnation pressure and at a stagnation temperature of $160^{\circ}$ 
$\mathrm{C}$ at this location. At 140-psia stagnation pressure the boundary layer thickness reduces to $3 / 10$ inches. The thickness of the boundary layer is about an order of magnitude larger than would normally be observed on a model, enabling detailed measurements of the flow field profiles. The incoming boundary layer will have some disturbances in it, even though it is laminar. These disturbances could include $1^{\text {st }}$-mode, $2^{\text {nd }}$-mode and Görtler waves. Prior to the experiment, the boundary layer will be surveyed and the effects of these disturbances will be characterized. The roughness element will sit on a metal blank fitted to a window opening. Additional windows allow for observation of the wake behind the element. Hot wire, fast dynamic pressure transducers, temperature sensitive paint and oil flows will be used to characterize the flow field. This effort will be conducted in collaboration with researchers at NASA, the University of Minnesota and the University of California at Los Angeles and will provide validation data for modeling and numerical studies.

\subsection{Hypersonic boundary layer transition (Hy-BoLT) experiment}

NASA has designed a wedge-like nose cone with rounded shoulder, see Fig. 4, to fly on the first flight of the ATK-GASL ALV X-1 rocket, see Fig. 5. This rocket has a gross weight of 43,000 lbs, a length of $54 \mathrm{ft}$, a diameter of 50 inches, and can achieve a maximum Mach number of 12.6. The flight is expected to take place in October 2007 from NASA's facility at Wallops Island, Virginia. The wedge-like nose carries on each side a plate of about 24 inches by 90 inches which will be instrumented to measure boundary layer transition. One side of the wedge will be used to study natural boundary layer transition. Numerical simulations indicate that the surface streamlines will turn towards the shoulders of the wedge, because of the lower pressure on this conical region. Due to the combined effect of cold wall and leading edge bluntness, the growth of $1^{\text {st }}$ mode and $2^{\text {nd }}$-mode instabilities will not be great enough to cause boundary layer transition, however, the simulations predict that in the Mach number range of 3 to 4.5 (at about 33 seconds to 44 seconds into the flight) the laminar boundary layer will transition due to cross-flow instability [35]. The transition line, located towards the shoulders, is expected to move from about 20 inches from the nose at Mach 3 to about 40 inches at Mach 4. The plate will be heavily instrumented with thermocouples, dynamic pressure gages, hot film gages and a boundary layer pressure rake. High-frequency instrumentation in the range of 20 to $100 \mathrm{kHz}$ will be used to identify velocity fluctuations and pressure disturbances associated with the cross-flow instability. The data will be reduced in flight by an onboard computer and transmitted to the ground. On the other side of the wedge a roughness transition experiment will be conducted to provide additional data to the boundary layer Shuttle return to flight tool set [12]. This experiment will take place at about Mach 7, or about 55 seconds into the flight. Transition on this side will be triggered by 3 protuberances located at about 20 inches from the nose of the wedge. One protuberance will be $5 \times 5 \times 0.5$ inches in dimension, another will be $5 \times 5 \times .05$ inches in dimension and the last one will be a cavity $2.75 \times 0.92$ inches and 0.38 inches deep. A total of 99 strategically located thermocouples will be used to map the transition zone associated with each trip. For more details on this and other experiments see References [36] and [37]. 


\section{Summary}

The Aerodynamic, Aerothermodynamics, and Plasmadynamics discipline of NASA's Hypersonic Project has an extensive research effort to develop and validate predictive tools to enable NASA critical missions such as the Highly Reliable Reusable Launch Systems and the High Mass Mars Entry Systems. In this review some of the critical components of this effort have been described including some of its modeling, computational and experimental activities. The program is still evolving and additional collaborative efforts both through partnerships with other government agencies, industry and universities are expected in the coming years.

\section{References}

[1] Mansour, N., Pittman, J. and Olson, L., "Fundamental Aeronautics Hypersonics Project at NASA: Overview”, AIAA Paper No. AIAA-2007-4263, June 2007.

[2] Cockrell, C. E.., Jr., "Aerosciences, Aero-Propulsion and Flight Mechanics Technology Development for NASA's Next Generation Launch Technology Program”, AIAA Paper No. 2003-6948, AIAA International Space Planes and Hypersonic Systems and Technology Conference, Norfolk, VA, December 2003.

[3] Curran, F., et al "The Benefits of Hypersonic Airbreathing Launch Systems for Access to Space”, AIAA Paper No. AIAA-2003-5265, 39 ${ }^{\text {th }}$ AIAA/ASME/SAE/ASEE Joint Propulsion Conference, Huntsville, AL, July 2003.

[4] Bertin, J. J. and Cummings, R. M., "Critical Hypersonic Aerothermodynamic Phenomena”, Annu. Rev. Fluid Mech. 2006, 38, pp129-157.

[5] Braum, R. D. and Manning, R. M., "Mars Exploration Entry, Descent and Landing Challenges” JSR, Vol. 44, No. 2, March-April 2007.

[6] Wright, M., Edquist, K. and Hollis, B., "Status of Aerothermal Modeling for Current ad Future Mars Exploration Missions”, Paper 428, 2006 IEEE Aerospace Conference, Big Sky, MT, March 2006.

[7] Bose, D. and Wright, M. J., "Uncertainty Analysis of Laminar Aeroheating Predictions for Mars Entries”, AIAA Paper No. AIAA-2005-4682, June 2005.

[8] Tirsky, G. A., "Up-to-date Gasdynamic Models of Hypersonic Aerodynamics and Heat Transfer with Real Gas Properties”, Annu. Rev. Fluid Mech. 1993, 25, pp 151-181.

[9] Cheng, H. K, "Perspectives on Hypersonic Viscous Flow Research", Annu. Rev. Fluid Mech. 1993, 25, pp 455-484.

[10] Gnoffo, P. A., "Planetary-entry Gas Dynamics”, Annu. Rev. Fluid Mech. 1999, 31, pp 459-494.

[11] Schneider, S. P., "Hypersonic Laminar-Turbulent Transition on Circular Cones and Scramjet Forebodies”, Progress in Aerospace Sciences, 40, 2004, pp 1-50.

[12] Berry, S. A, et al, "Overview of Boundary Layer Transition Research in Support of Orbiter Return to Flight”, AIAA Paper No. AIAA-2006-2918, 9 ${ }^{\text {th }}$ AIAA/ASME Joint Thermophysics and Heat Transfer Conference, San Francisco, CA, June 2006.

[13] Reed, H. L., Saric, W. S. and Arnal, D., "Linear Stability Theory Applied to Boundary Layers”, Annu. Rev. Fluid Mech. 1996, 28, pp 389-428.

[14] Herbert, T., "Parabolized Stability Equations”, Annu. Rev. Fluid Mech. 1997, 29, pp 245-283. 
[15] Kleiser, L. and Zang, T., "Numerical Simulation of Transition in Wall-Bounded Shear Flows”, Annu. Rev. Fluid Mech. 1991, 23, pp 495-537.

[16] Candler, G. V. and Olejniczak, J., "Nitrogen Dissociation Rates in Complex Hypersonic Flows”, AIAA Paper No. AIAA-1997-2500, June 1997.

[17] Schwenke, D. W., "Calculation of Rate Constants for the Three-Body Recombination of $\mathrm{H}_{2}$ in the Presence of $\mathrm{H}_{2}$ ”, J. of Chem. Phys., 89, 1988, pp 2076-2091. [18] Modest, M. F., "Radiative Heat Transfer”, $2^{\text {nd }}$ Edition, Academic Press, NY, 2003. [19] Park, C., "Calculation of Nonequilibrium Radiation in the Flight Regimes of Aeroassisted Orbital Transfer Vehicles", Thermal Design of Aeroassisted Orbital Transfer Vehicles, 96, 1985, pp 395-418.

[20] Hartung, L. C., "Predicting Radiative Heat Transfer in Thermochemical Nonequilibrium Flow Fields”, NASA TM 4564, 1994.

[21] Modest, M. F., "Narrow-Band and Full-Spectrum k-Distribution for Radiative Heat Transfer”, J. Quant. Spectrosc. Radiat. Transfer, 76, 2003, pp 69-83.

[22] Yang, J. and Modest, M. F., "Elliptic PDE Formulation of High-Order P-N Approximations for Radiative Transfer", Int. J. Heat Mass Transfer, to appear, April 2006.

[23] Viswanath, K., et al, "Investigation of Soot Combustion in Underexpanded Jet Plume Flows”, J. Thermoph. Heat Transfer, 19, 2005, pp 282-293.

[24] Gnoffo, P., "Upwind-Biased Point-Implicit Relaxation Strategies for Viscous Hypersonic Flows”, AIAA Paper No. AIAA-89-1972, June 1989.

[25] Wright, M., Candler, G. V. and Bose, D., "Data-Parallel Line Relaxation Method for the Navier-Stokes Equations”, AIAA J., 36, 1998, pp 1603-1609.

[26] Nompelis, I., Drayna, T. W. and Candler, G. V., "A Parallel Unstructured Implicit Solver for Hypersonic Reacting Flow Simulation”, AIAA Paper No. AIAA-2005-4867, June 2005.

[27] Hash, D., et al, "FIRE II Calculations for Hypersonic Nonequilibrium Aerothermodynamics Code Verification: DPLR, LAURA and US3D”, AIAA Paper No. AIAA-2007-005, January 2007.

[28] Bird, G. A., "Molecular Gas Dynamics and the Direct Simulation of Gas Flows", Clarendon Press, Oxford, 1994.

[29] Barth, T., "On Discontinuous Galerkin Approximations of Boltzmann Moment Systems with Levermore Closure”, CMAME, Vol.195, 2006, pp 3311-3330.

[30] Yoon, S., Gnoffo, P., White, J., and Thomas, J., "Computational Challenges in Hypersonic Flow Simulations”, AIAA Paper No. AIAA-2007-4265, June 2007.

[31] Holden, M. S. and Parker, R. A., "LENS Hypervelocity Tunnels and Application to Vehicle Testing at Duplicated Flight Conditions", Chapter 4 of Advanced Hypersonic Test Facilities, Lu, F. K. and Marren, D. E. Eds. AIAA Progress in Astronautics and Aeronautics Series, Vol. 198, Reston, VA, 2002.

[32] Danehy, P., et al, "Planar Laser-Induced Fluorescence (PLIF) Investigation of Hypersonic Flowfields in a Mach 10 Wind Tunnel”, AIAA Paper No. AIAA-2006-3442, June 2006.

[33] Schneider, S. P., "Laminar-Flow Design for a Mach-6 Quiet-Flow Wind Tunnel Nozzle”, Current Science, 76, September 2000, pp 70-799.

[34] Skoch, C., "Disturbances From Shock/Boundary-Layer Interactions Affecting Upstream Hypersonic Flows”, Ph. D. Thesis, Purdue University, December 2005. 
[35] Malik, M., "eMalik3D: An $e^{N}$ Code for Three-Dimensional Flow Over Finite Swept Wings”, High Technology Report No. HTC-9502, April 1995.

[36] Berry, S., Chen, F., Wilder, M. and Reda, D., "Boundary Layer Transition Experiments in Support of the Hypersonics Program", AIAA Paper No. AIAA-20074266, June 2007.

[37] Horvath, T., Berry, S., Blanchard, R., Schwartz, R., Ross, M. and Tack, S., "Shuttle Entry Imaging Using Infrared Thermography”, AIAA Paper No. AIAA-2007-4267, June 2007. 


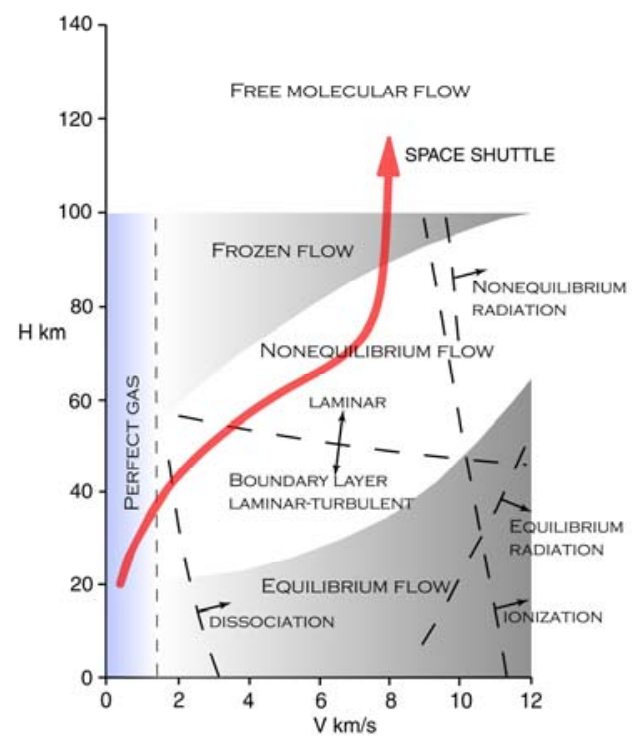

Figure 1. Flow regimes encountered in hypersonic flow as a function of vehicle speed and altitude. For reference a typical Space Shuttle trajectory is drawn.

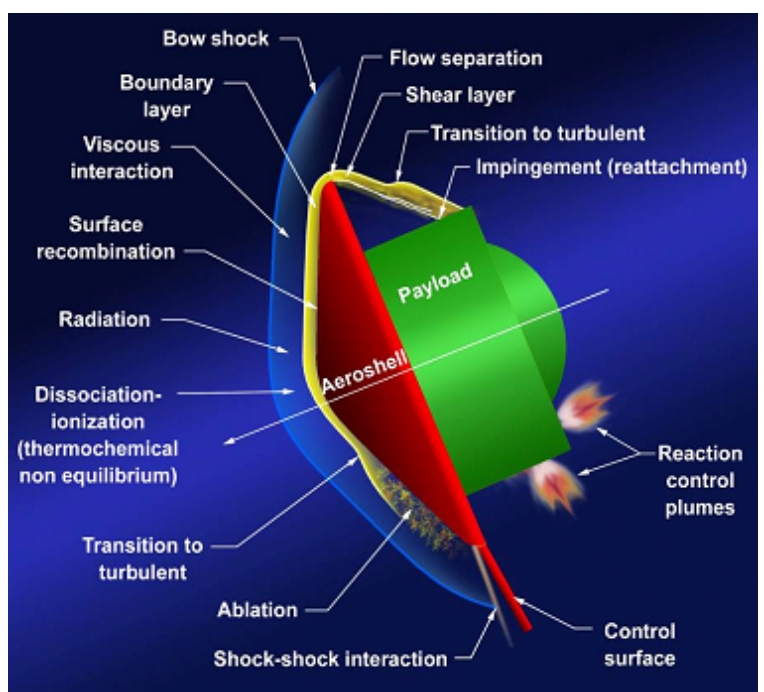

Figure 2. Typical flow features of a reentrycapsule. 


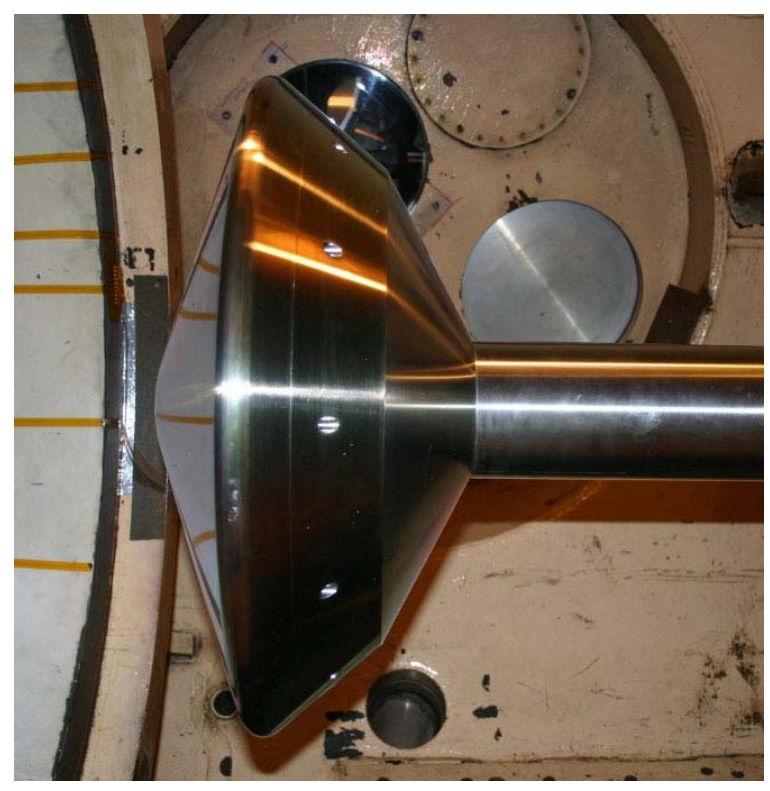

Figure 3. MSL $70^{\circ}$ sphere-cone model for test at the LENS II CALSPAN facility.

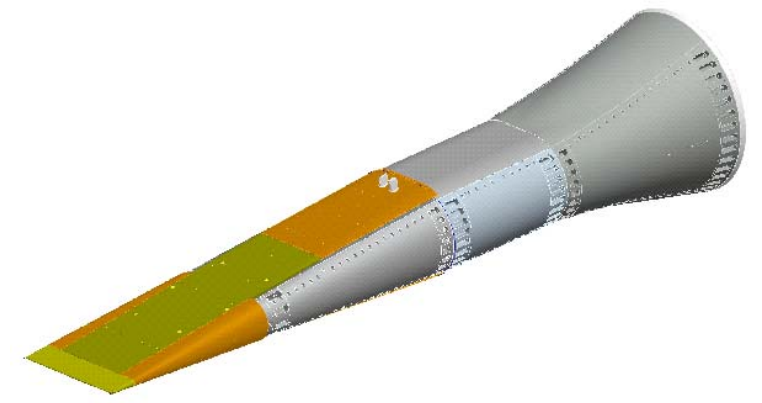

Figure 4. Hy-BoLT nose cone configuration.

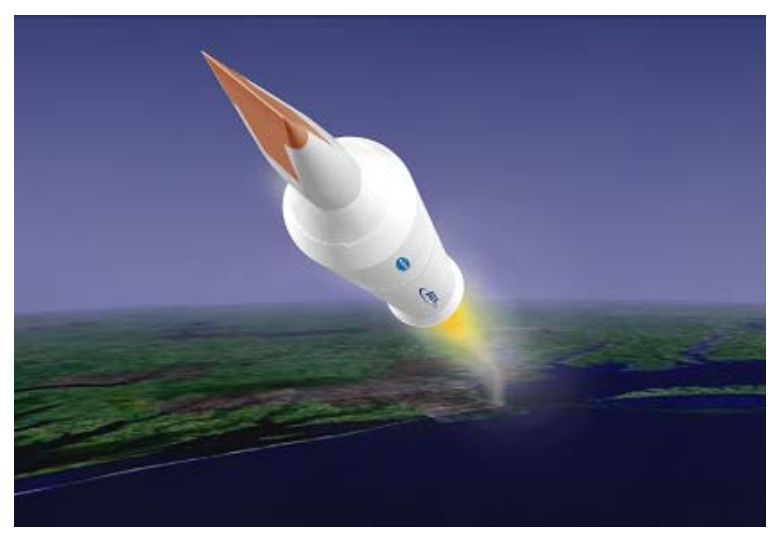

Figure 5. Artist rendition of Hy-BoLT nose cone riding on ATK GASL's ALV-X1 rocket. 